\title{
Teaching Buddhist Vocabulary to the Undergraduates of the Buddhist and Pali University of Sri Lanka
}

\author{
Nipunika Dilani \\ Dept. of English, Buddhist and Pali University of Sri Lanka \\ Gurulugomi Mawatha, Pitipana North, Homagama, 10206, Sri Lanka
}

Received: August 18, 2021 Accepted: September 3, 2021 Published: September 6, 2021

doi:10.5296/jsel.v9i1.18991ＵRL: https://doi.org/10.5296/jsel.v9i1.18991

\begin{abstract}
Learning Buddhist terms in English is one of the main challenges that the English medium undergraduates of the Buddhist and Pali University of Sri Lanka face. As the majority of the undergraduates start English medium education for the first time in the university they struggle a lot to learn the Buddhist terms necessary for their studies in English medium. Moreover, the students need a wide range of productive vocabulary in preaching the Buddha's Dhamma worldwide which is one of the prime objectives of the university. Traditionally, vocabulary teaching has been paid less attention and the most common way is giving vocabulary lists for students to memorize. However, the current study as one of its objectives proves that this traditional approach to vocabulary teaching is less effective as well as less interesting. As the second objective, the study introduces a task-based integrated approach to teach Buddhist terminology. Being mixed research the study has employed instruments like vocabulary tests, questionnaires and interviews with the students as well as the lecturers in addition to classroom observation. The study finds that an integrated approach through tasks as material followed by an eclectic teaching method based on the post method is more effective than teaching through vocabulary lists.
\end{abstract}

Keywords: Buddhist terminology, undergraduate, vocabulary, task-based, integrate, post method, eclectic 


\section{Introduction}

"Without grammar very little can be conveyed, without vocabulary nothing can be conveyed"(Wilkins, 1972, p. 111).

This statement underscores the significance of the vocabulary without which no language function could be performed. Likewise, academic vocabulary is an essential component of academic achievement, and vocabulary is the primary challenge faced by L2 learners when entering university (Kieffer et al., p.2014). The undergraduates of the Buddhist and Pali University of Sri Lanka are mostly Buddhist monks who follow subjects related to Buddhism and face the same challenge in continuing their studies in the English medium. Most of the undergraduates start English medium education at the university and find it challenging to learn the Buddhist terminology which is essential for their education. Perin(2015) and Wallace (2008) also have addressed a similar issue and find that insufficient vocabulary is one of the primary difficulties that students face in university-level language acquisition. Further, learning academic vocabulary rather than general vocabulary is found to be more challenging. Academic vocabulary is an essential component of academic achievement, and vocabulary is the primary challenge faced by L2 learners when entering university (Kieffer et al., p.2016). This problem appears to have a common appeal in different contexts. Accordingly, this paper investigates methods to teach Buddhist terminology effectively to undergraduates.

\subsection{The Research Problem}

The prime objective of establishing the Buddhist and Pali University of Sri Lanka is to train the Buddhist savants in the propagation of true Theravada Buddhism locally and internationally. The competence of English with a wide range of Buddhist vocabulary is essential to achieve this objective as well as other academic objectives of the students.

As a lecturer of English at the Buddhist and Pali University of Sri Lanka the researcher has observed students struggling to learn English vocabulary related to Buddhism. Not only that the other lecturers who teach Buddhism-related subjects also normally complain that one major reason for the poor performance of the undergraduates at the examination is the low Buddhist word stock they own. Moreover the students also constantly inquire about the effective ways that they can learn vocabulary. Most importantly the lecturers of the "Preaching the Dhamma in English" course that trains the students in the skills to preach the Buddha's Dhamma in English worldwide have observed that the inadequacy of the Buddhist terminology is one of the major barriers in the accomplishment of this mission. Thus the research problem is the insufficiency of Buddhist vocabulary in English of the undergraduates for their studies as well as the Dhamma preaching.

\subsection{Research Questions}

How do the undergraduates learn Buddhist vocabulary now?

What are the issues encountered by the undergraduates in learning Buddhist vocabulary in English?

How could those problems be solved? 
What are the innovative ways to teach Buddhist vocabulary?

\subsection{Objectives}

The current study is conducted to achieve few main objectives. The first objective is to study the way the undergraduates learn Buddhist vocabulary currently. The second objective is to monitor the success/failure of the current process of learning vocabulary. And new tasks and activities based on TBLT will be introduced to teach/learn vocabulary integratively. Finally, the effectiveness of newly introduced methods will be studied in comparison with the methods the students are currently using.

\section{Methodology}

\subsection{Participants}

There are only fifteen English medium undergraduates who are following the "Preaching the Dhamma in English Course" conducted by the Department of English of the Buddhist and Pali University of Sri Lanka. Considering the uniformity of the sample only those 15 students have been selected as the participants of the current study.

\subsection{Instruments and Procedure}

In pursuit of the above objectives, both quantitative and qualitative methods are employed. Thus this belongs to the mixed type of research which involves "combine quantitative and qualitative approaches to a study" (Tashakkori \& Teddlie 1998,p,1). And also considering the evolutionary stages of mixed research the current study belongs to "multi-application within the stage" where "quantitative and/or qualitative" approaches have been used in the "type of inquiry", "data collection/operation" and "analysis/operations" (ibid,15). As quantitative method interviews were conducted to study the problems they face in learning vocabulary and the methods they follow currently to learn vocabulary. Further according to the traditional method 100 words and phrases related to Buddhist discourses were given for them to study. After two weeks a test based on those 100 words and phrases was given to measure their vocabulary knowledge. Then the researcher intervened in the study by teaching another 100 items/ phrases of the vocabulary of similar level through some task-based exercises integrated with reading, writing and speaking which fit a task-based framework. And in the process of teaching, the researcher followed the eclectic method rather than limiting herself to one teaching method. After two weeks another test based on the second 100 vocabulary items was given to them. Finally, the results were compared. In addition to this, classroom observation was done that "enables the researcher to combine it with questionnaires and interviews to collect "relatively objective firsthand information" (Johnson \& Turner 2003, p. 314). This observation belongs to qualitative study which studies "things in their natural settings attempting to make sense of, or interpret, phenomena in terms of the meanings people bring to them"(Denzin \& Lincoln, 2005, p.3). And further qualitative research involves methods like "personal experience; introspect; life story; interview..." (ibid) which also have been used in the current study. The data collected using the above instruments and sources have been 
interpreted and analysed applying qualitative, quantitative and comparative data analysis methods to reach conclusions.

\section{Literature Review}

This section includes a narrative literature review which presents a comprehensive background of the literature related to the current topic in order to highlight new research streams, identify gaps and to recognize inconsistencies (Coughlan et al., 2007).

\subsection{What Vocabulary to Learn}

Richards and Renandya (2002, p.255) provide an explicit introduction to vocabulary as the "core component of language proficiency" and emphasizes its significance as the "basis for how learners speak, listen, read and write". Learning a word means learning the word's meaning, the spoken form, the written form, the grammatical patterns, collocations, frequency, appropriateness and associations (Schmitt,2000 ; Nation,1990 \& Nation and Newton,1997 cited in Altyari, 2017).

Among various categorizations of the vocabulary type core and non-core is one basic type. While core vocabulary refers to the words that "occur frequently and are more central to the language than other words" (Carter, 1988, p.155) non-core vocabulary refers to subject-specific vocabulary because of its lack of neutrality and association with a specialized topic (ibid,p.172). Buddhist vocabulary can be introduced as non-core and semi-technical which is used in general language with a higher frequency of occurrence in specific and technical descriptions and discussions (ibid,p.157). Most of the Buddhist terms are general English terms that convey specific meanings depending on the context. Another common categorization of vocabulary is presented by Nation (2001) as high-frequency words, low-frequency words and specialized words. A wide range of Buddhist vocabulary that could be categorized as high-frequency academic words is essential for academic as well as missionary purposes of the undergraduates.

\subsection{Teaching Vocabulary}

Different approaches to teach/learn vocabulary have been used throughout history. Grauberg(1997) introduces five stages of learning vocabulary as discrimination, understanding meaning, remembering, consolidation and extension of meaning which help the learners as well as the teachers to follow. National Reading Technical Assistance Center (2000) researched teaching vocabulary related to reading to study their effectiveness. The research finds that frequent exposure to target vocabulary, explicit instruction on them, questioning and language engagement while teaching a reading text are effective ways in vocabulary learning. Further, an explicit explanation of words with a simple example rather than reading the dictionary meaning is helpful for comprehension of the meaning (ibid,26). The TRA (Teacher Reading Academy, 2002) has developed materials to teach vocabulary based on research. Among the instructions presented by them, encouraging wide reading, exposing students to high-quality oral language, promoting word consciousness, teaching word meaning directly, teaching independent 
word-learning strategies, including the use of context clues, using of word parts, and the dictionary are some effective methods that help in teaching vocabulary to the students. However, it is clear those methods are used by many teachers and some are indirect ways that students themselves can practice in improving vocabulary.

\subsection{Theoretical Basis}

Language teaching has gone by several decades especially since the systematic approaches to language teaching were introduced. A vast body of literature has been emerged related to language teaching along with vocabulary teaching starting from the grammar-translation method to the communicative teaching method and since the late 1980s a shift to an anti-method movement in the field (Bax 2003; Pennycook 1989; Phillipson 1992; Prabhu 1990 cited in Safari \& Rashidi, 2015). These types of paradigm shifts have taken place out of insensitivity of methods in application to different EFL/ESL. Rodgers (2000) calls the past century the "age of methods" as there was a change in language teaching methods from grammar-translation method (GTM), and direct method to alternative methods (Richards \& Rodgers, 2003). These methods restrict the teachers and learners into their boundaries allowing a narrow room for creativity, experience, knowledge to be utilized in the classroom. In teaching vocabulary also the teachers are restricted to a limited framework that does not allow their innovation. And also these teaching methods concern less practicality when it comes to different contexts.

The researchers have tried applying the post method in different language teaching contexts and have found both positive and negative aspects of it. In applying it to the Iranian EFL context, Safari \& Rashidi (2015) found that the application of post method pedagogy in Iran would not be simple but a lot of financial investment, instruction, the provision of resources and opportunities would have been employed. Akbari (2008) also believes that despite the emancipatory role of the post method, it is more concerned with philosophy and philosophical teaching without any consideration of actual practice in each EFL teaching context. Kumaravadivelu(2006) points out that no single perfect method fits language teaching conditions in different contexts. So introducing the post method pedagogy he emphasizes that the pedagogic parameters of particularity, practicality, and possibility should be considered by the teachers. The advancement of a context-sensitive pedagogy based on the true understanding of local linguistic, sociocultural, and political particularities matches with language teaching rather than borrowing a teaching method that is developed in a totally different context. He emphasizes the importance for the teachers to theorize from their practice and to practise what they theorize. And he further stresses the importance of larger social, political, educational, and institutional forces that shape identity formation and social transformation. Accordingly, the teachers who are well aware of the learners and the teaching context have the freedom to choose the methods and materials based on the experience. Accordingly, the researcher plans to employ an eclectic approach that blends different teaching methods considering the level and preference of the students rather than restricting to one single framework. As the post method explains while those teaching methods suit to certain situations they do not match to every context across the world. In teaching vocabulary also as the post method explains teachers can adopt different methods depending on their experience 
on the teaching context.

Despite these different ideas related to teaching methods the task-based teaching is found to be successful as an approach to be followed in preparing vocabulary lessons. Task-based language teaching (TBLT) which Richards and Rodgers (2001, p.223), defined as "an approach based on the use of tasks as the core unit of planning and instruction in language teaching" has been often adopted in vocabulary teaching in different contexts. They believe that TBLT draws on functional, interactional and, in some cases, structural models of language mingled in the processes of pre-task, during the task, and post-task. In applying TBLT into subject-specific vocabulary teaching in the computer center at the University of Costa Rica, Cubillo and Brenes (2009) find that the advantages of using Task-based learning to infer the rule of the superlative form of adjectives in English. Thus implementing task-based instruction, learners, as well as teachers, will certainly benefit from a different approach to language pedagogy because it is more motivating, challenging, innovative, appealing and meaningful to students than other traditional grammar-translation-based approaches.

TBLT is a modern development in language teaching in contrast to traditional methods and approaches. However, the method hasn't been tried very much to use for Buddhist vocabulary teaching in Sri Lanka. The traditional method of giving vocabulary lists with meaning in Sinhala or English to corresponding Pali terms is the commonly practiced vocabulary teaching method in most monastic educational institutes. Therefore this section shows a vacuum related to teaching Buddhist vocabulary in English in the body of existing literature.

The survey of related literature makes it clear that the post method that removes many restrictions suits in vocabulary teaching to undergraduates here as the students represent a sample from different areas of the country as well as from different countries with varying backgrounds. Further, TBLT has been successfully used in different contexts yet a gap for research that amalgamates post method and TBT into Buddhist vocabulary teaching could be traced through the literary survey.

\section{Research findings and Discussion}

\subsection{How Undergraduates Learn Buddhist Vocabulary Currently}

The undergraduates are expected to have a wide range of vocabulary and the students $(85 \%)$ have confirmed the essentiality of vocabulary for different purposes like preaching the Dhamma in English and university studies. The students follow different ways in learning vocabulary and among them common techniques are memorizing vocabulary lists, writing and reading repetition. In addition to explaining the vocabulary in the reading texts then and there, the common practice among the teachers is asking to write down the new terms and learn their meaning. In the preaching the Dhamma in English course the students are taught Buddhist terminology in a separate module to train them for preaching the Dhamma in English. However, that short exposure does not provide an ample range of Buddhist terminology necessary for undergraduate studies as well as for the practical needs of their lives. And it also sometimes follows the same traditional method. Even if the students learn the meaning of the words from 


\section{Macrothink}

the above processes that cannot be regarded as knowing the meaning of a word as it is not sufficient enough learn vocabulary.

As a part of the research plan, the current study provided the students with a list of 100 words and phrases and asked them to learn. After one week they were given a small test to check how far they have learnt the given vocabulary. Only six students have scored more than 25 out of 50 . Thus the poor results of the test show the ineffectiveness of the learning vocabulary as list memorization. The main reason for this failure may be the reason that Nation(2001) mentions as isolated word lists that have no contextual reference do not teach the usage of words. Applying the researcher's personal introspect here it is obvious that if the students are trained to use the words in different contexts that would give better results in learning and memorizing. Finally, it is clear that the typical way of learning vocabulary lists is less productive.

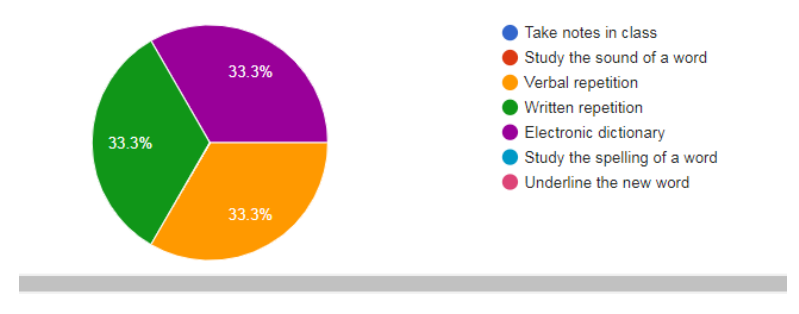

Figure 1. Current ways of learning Buddhist terms

In addition to the memorizing lists as the above figure shows the students use an electronic dictionary, verbal repetition and written repetition as techniques of vocabulary learning. However, it is clear that these methods are related to productive vocabulary and give little chance to use and apply them. Likewise, it is again clear that making the students use them very often is more effective.

4.2 What Are the Issues Encountered by the Undergraduates in Learning Buddhist Vocabulary in English?

The students have unanimously agreed on the high importance of learning Buddhist terminology for their studies as well as their daily functions as Buddhist monks. And with the same force, they have mentioned the difficulty in learning the Buddhist terminology. Among the few aspects given about learning the words, they have mentioned that learning the usage and meaning are the most difficult. 
Figure 2. Difficulties in learning Buddhist terms

Word lists have by no means any meaningful context. They are typically organized words. Teachers generally tell learners to memorize the words with the definitions but they don't provide any training on how to do this. On the other hand, dictionary use is a kind of language-focused learning in which learners consult dictionaries to pick up the meaning of the words (Nation, 2001). They have mentioned that they need plenty of Buddhist terms for their studies but lack of that knowledge is a great issue they have.

\subsection{Suggested Solutions}

The researcher intervenes with a solution to the said problem introducing task-based lessons followed by an eclectic method of teaching in line with the post method instead of conventional vocabulary teaching. As the above figure points out the students also have mentioned that the usage is the most difficult for them to which the researcher also agrees. In conformity with that, the tasks were designed mostly for the students to use the Buddhist terms in written and vocal format. The students were given different vocabulary tasks integrated with other skills and the tasks were discussed with the students after they attempt to complete them. For example, one task was a small reading passage extracted from a Jataka story and another was a listening to a short Dhamma preaching. In these instances, more emphasis was put on meaning and the usage of the words while explaining the texts. The tasks set on the text allowed using the terms in different ways. In teaching/discussing activities different teaching methods were utilized without adhering to one method to cater to all types of students. Thus the main focus of the researcher was paid to teach the usage of the words aligned with the students' difficulty and the researcher's observation.

\subsection{The Effectiveness of the Solutions}

A great interest in the students could be observed in doing the activities. They have mentioned in the questionnaire that the tasks were interesting and they enjoyed completing the tasks. After two weeks of doing these tasks, a test based on the taught vocabulary was given and the results of the test proved the effectiveness of the new method. A comparison of the results of the two tests stands as the best proof to understand the difference between the two methods. 


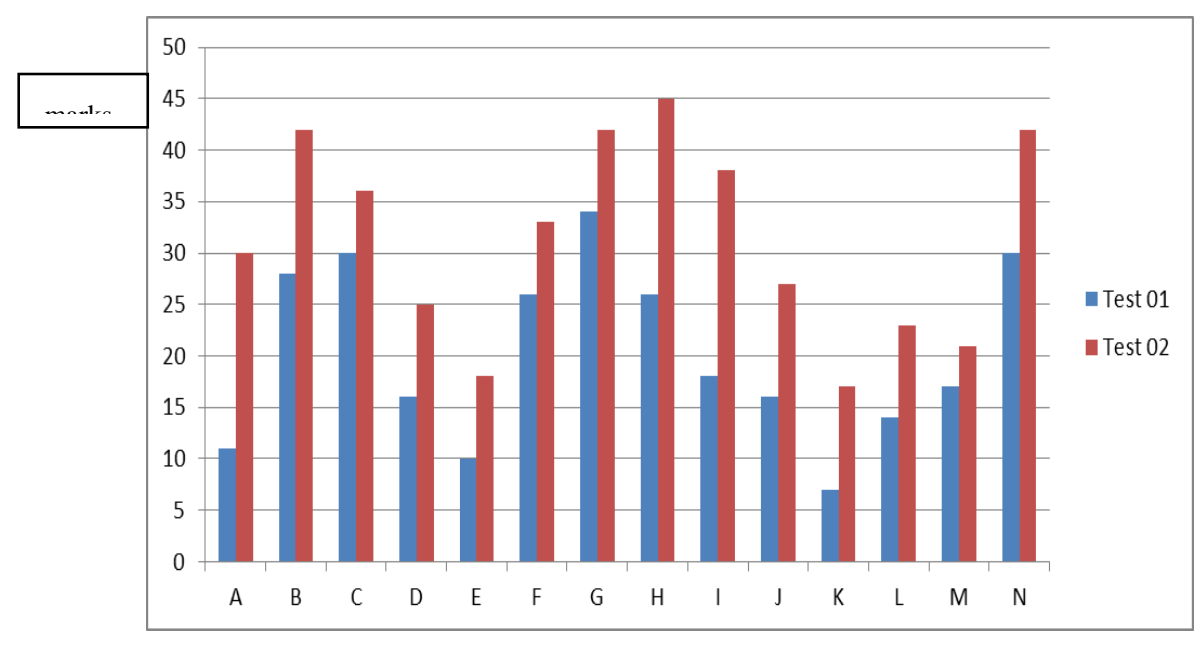

Figure 3. Comparison of the results ${ }_{\ldots+\ldots+\ldots+n}^{\text {tests }}$

As this bar chart shows that no student has scored even 35 for the first test whereas 6 students have got more than 35 marks for the second test. And also every student has got some marks more for the second test than the first test. Likewise, the results of the second test very clearly show the impact of the teaching materials and the method on the students.

\section{Conclusion}

Many implications regarding the vocabulary learning patterns, their effectiveness, new methods, etc have emerged in this research. First, it is very clear that the students should have a wide range of Buddhist vocabulary for their studies and other functions. Secondly, the current method they follow is learning the vocabulary lists by heart. However, this method has been proven to have a less positive impact on the students. Then as a solution to overcome this issue the students were exposed to task-based activities integrated into other skills. The study finds this approach more effective than the former. In this manner, finally, it is obvious that task-based approach produces good results in teaching Buddhist vocabulary in English. As a teaching method, an eclectic method based on the post method philosophy is found to be suitable for teaching Buddhist vocabulary.

\section{References}

Akbari, R. (2008). Postmethod discourse and practice. TESOL Quarterly, 42(4), 641-652.

Altyari, A.W. (2017). English Vocabulary Uptake by Saudi Arabc Speaking Students at Public Schools. British Journal of English Linguistics, 5(1), 10-16.

https://www.eajournals.org/wp-content/uploads/English-Vocabulary-Uptake-by-Saudi-Arabic -speaking-students-at-Public-Schools.pdf 
Beck, I. L, McKeown, M. G, Kucan, L. (2013). Bringing vocabulary into life: Robust vocabulary instruction. New York: The Guilford Press. https://books.google.lk/books

Brooks, M. (no date). The Role of Vocabulary in English for Specific Purposes (ESP) Teaching and Learning, Considerations for Asia University. https://core.ac.uk

Carter, R., \& McCarthy, M. (1988).Vocabulary and Language Teaching. London and New York: Longman.

Coughlan. M., \& Ryan, F. C. P. (2007). Undertaking a literature review: a step by step approach.

https://www.researchgate.net/publication/5454130_Undertaking_a_literature_revw_A_step-b y-step_approach

Johnson, B., \& Turner, L. A. (2003). Data collection strategies in mixed methods research. In Keiffer, M. J, Lesaux, N. K, Kelley, J. G, Harris, J. R. (2014). Effects of Academic Vocabulary Instruction for Linguistically Diverse Adolescents: Evidence From a Randomized Field Trial. American Educational Research Journal, 51(6), 1159-1194.

http://dx.doi.org/10.3102/0002831214532165

Kumaravadivelu, B. (1994). The postmethod condition: Emerging strategies for second/foreign language teaching. TESOL Quarterly, 28(1), 27-48.

Kumaravadivelu, B. (2001). Toward a postmethod pedagogy. TESOL Quarterly, 35(4), 537-560.

Kumaravadivelu, B. (2003). A postmethod perspective on English language teaching. World Englishes, 22(4), 539-550.

Nation, I. S. P. (2001). Learning Vocabulary in Another Language. Cambridge: Cambridge University Press.

National reading Technological Assistance Center. (2010). A Review of the Current Research on Vocabulary Instruction. https://www2.ed.gov/programs/readingfirst/support/rmcfinal1.pdf

Newton, J. (1995). Task-based interaction and incidental vocabulary learning: a case study, Sage Journals, 11(2), 159-176.

https://journals.sagepub.com/doi/abs/10.1177/026765839501100207

Richards, J. C., \& Renandya, W. A. (2002). Methodology in language teaching. Cambridge: Cambridge university press. http://dx.doi.org/10.1017/CBO9780511667190

Safari, P., \& Rashidi, N. (2015). A Move towards Post method Pedagogy in the Iranian EFL Context: Panacea or More Pain? PASAA, Vol. 50 https://files.eric.ed.gov/fulltext/EJ1088314.pdf

Tashakkori, A., \& Teddie, C. (Eds.) (1998). Handbook of mixed methods in social and behavioral research (pp. 297-319). London: Sage. https://books.google.lk 
Wilkins, D. A. (1972). Linguistics in Language Teaching. Australia: Edward Arnold.

\section{Copyright Disclaimer}

Copyright for this article is retained by the author(s), with first publication rights granted to the journal.

This is an open-access article distributed under the terms and conditions of the Creative Commons Attribution license (http://creativecommons.org/licenses/by/4.0/). 